\title{
User Acceptance of Personalized and Context-Specific Online Advertising
}

\author{
S. Denise Ruhrberg, Giulia Kirstein, Katsiaryna S. Baran \\ Information Science, Heinrich-Heine-University, Düsseldorf, Germany \\ Email:kirstein.ruhrberg@gmail.com
}

How to cite this paper: Ruhrberg, S.D., Kirstein, G. and Baran, K.S. (2017) User Acceptance of Personalized and ContextSpecific Online Advertising. Open Journal of Social Sciences, 5, 223-232. https://doi.org/10.4236/jss.2017.53020

Received: January 24, 2017

Accepted: March 27, 2017

Published: March 30, 2017

Copyright $\odot 2017$ by authors and Scientific Research Publishing Inc. This work is licensed under the Creative Commons Attribution International License (CC BY 4.0).

http://creativecommons.org/licenses/by/4.0/

\section{(c) (i) Open Access}

\begin{abstract}
Over the years, society's character has shifted from a pure attention to a contributing model. Due to the internet's evolution over the past decades, the users' role has changed from a passive spectator to an active part of the information process. This can be observed by an increasing demand on interaction possibilities by users. Advertisements which offer user participation for example achieve higher attention rates than static banners. Within this study, user acceptance of personalized and context-specific online advertising has been investigated. For this purpose, users' reactions on personalized advertisements on the Social Network Service (SNS) Facebook in relation to context-specific placed advertisements via the online advertising system Google AdWords have been evaluated. Using an online questionnaire, an anonymous survey was conducted, which was aimed at the broad mass of internet users. Key issues were the general perception of online advertisings and the interaction with these. This paper provides insights for advertisers on different generational cohorts' and genders' attitudes towards personalized and context-specific advertising.
\end{abstract}

\section{Keywords}

User Acceptance, Marketing, Consumer Psychology, Consumer Behavior, Consumer, Advertisement, Advertising, Facebook, Facebook Ads, Google, Google AdWords, SERP, Search Engine, Social Media, Social Network Service

\section{Introduction}

The development of internet technologies and their spread (e.g. Cloud Computing, Social Media and mobile devices) affect media, economy and everyday life, leading to a change of media usage behavior. Due to the transformation to Web 2.0, website operators do not own the sole privilege of content creation, commenting and sharing-even the user has the opportunity to do so [1]. Nowadays, 
advertisers rely either on different modes of interactive technology like Social Network Services (SNSs) or on e.g. television advertising to promote their services and products. Companies that want to offer their product or service range via online shops can develop online trade as a new sales channel, but also consumers can order clothes and food easily from their homes. In contrast to marketing on TV, radio or print media, internet advertising is much cheaper, quickly to produce and can be flexibly adapted or replaced. Furthermore, the idea of executing content that is up to date and entertaining could get consumers to interact preferably for the respective advertiser [2]. According to Yaakop and Hemsley-Brown [3], this powerful attribute can be seen as a future of advertising and may become less abstract in consumers' minds than TV spots as marketing stimuli. Usually, conventional advertisements are accompanied by a great spreading loss for the advertiser; promotional advertising is also displayed to uninterested and therefore irrelevant users. However, in online marketing, the advertiser has many options to align his adverts accurately, such as determining target groups or by placing adverts on specific web pages. Another advantage of online advertising is the non-existent temporal limitation, wherefore adverts can be displayed at any time of the day. Promotional advertising on the internet mostly appears around the actual website content; a parallel perception of both can take place. Furthermore, the possibilities of digital advertising offer advertisers multiple options of gaining information about users on their website, even as real time evaluation. Companies have different ways of promoting their products and services as well as maintaining a positive image and increasing their popularity. A company's own website is considered as the center of online marketing, which should be promoted by search engine or e-mail marketing, as well as social media marketing and display advertisements. "More than 85 percent of respondents said they preferred an ad-supported Internet model instead of paying for online content [...]" [4]: These preferred internet models are associated with the voluntary disclosure of private information. In conclusion, these services are not financed by charging users money, but by merging the voluntarily supplied private information to digital profiles, which can be used for advertising purposes. This is known as personalized advertising [5]. The second major form of digital commercials is context-specific adverts. These are defined by automatic placing based on specific subscribed search arguments.

\section{Significance of the Study}

According to Boyd and Ellison [6], there is little research published in the area of consumer perceptions of advertising on social networking sites, although these sites have faced rapid growth over very short periods of time. Besides, little is known about how online factors influence internet users' attitudes towards online advertising [7]. Also, customer reactions to online advertising are often interpreted incorrectly due to lack of knowledge and limited research done on consumers' behavior towards online advertising. This causes advertisers to choose an inefficient advertisement strategy and an unclear identification of the 
target audience [2]. The investigation of user reception on online marketing is of particular relevance in the context of the rise of e-commerce and the associated increased influence of advertising on the consumer in the future. This influence is for example shown in the customer buying funnel model [8], which describes the five stages of a customer in the buying funnel from awareness of a product or service up to purchase it. Hence, the purpose of this study is to fulfill the research gap by examining the relationship between user perception and their interaction with personalized and context-specific advertising, using the context of Facebook and Google. The comparison of personalized and context-based advertising should point out which type of online marketing rather leads to acceptance.

The survey's respondents' age and gender depicts an import role for this empirical study, which presents different cohorts' opinions regarding online advertising. Especially with the use of social media, advertisers must understand the two extreme cases of generational cohorts, because they use the internet in different ways. People born in 1978 or later have grown up with digital technology. Digital communication is a part of their lives-their use of technology is intuitive and self-evident. Studies have shown that their way of thinking adapts to the use of technology. This first group is called Digital Natives. Digital Immigrants are people born before 1978 [9]. They take advantage of digital technologies as far as they are useful to them [10]. However, they get around less intuitive with them [11].

The research model (Figure 1) of this study illustrates the interplay of intergenerational differences as well as differences in gender, referring to their behavior characteristics. A broad user study was conducted concerning as many generational cohorts. Every participant on the user survey was classed by its specified age into one of the two categories, Digital Natives and Digital Immigrants. The users' perception of adverts subdivided into context-specific and

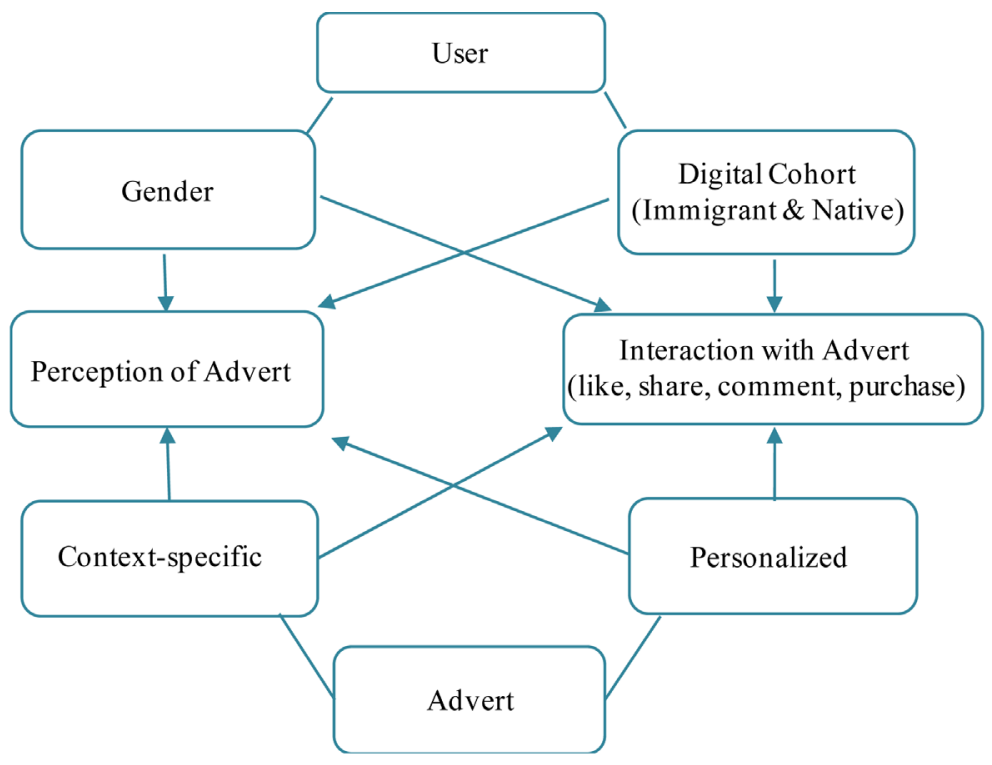

Figure 1. Research model. 
personalized and the interaction (like, share, comment, purchase) with these two subdivisions were examined. Finally, the results show if distinctions between the user groups exists.

This study aimed at investigating to illustrate the interplay of intergenerational differences between Digital Natives and Digital Immigrants referring to their behavior characteristics regarding to dealing with digital adverts, we hypothesize:

H1a: Digital Natives perceive online adverts rather than Digital Immigrants.

H1b: Digital Natives interact more often with digital adverts on Facebook than Digital Immigrants.

An empirical study of Van Slyke et al. [12] on gender differences on webbased shopping indicates that women do more product research on websites than men. For men, shopping is a goal-oriented process, which should be completed without any detours, whereas women usually try to acquire the best possible product. They compare and evaluate information and exchange views with each other, since personal advice is of high priority for them [13]. Bannister [14] figured out that women had a slightly more positive attitude to Facebook advertisings. We hypothesize:

$\mathrm{H} 2$ : Women notice digital adverts more often than men.

Based on the correctness of the previous hypotheses it should be proofed whether the perception of online adverts is accompanied by increased interaction. For this purpose, the sections of personalized and context-specific advertising based on the survey results were evaluated separately for Facebook and Google to be subsequently compared:

H3a: Women interact more often with digital adverts on Facebook than men.

H3b: Women interact more often with digital adverts on Google's search engine result page than men.

\section{Research Methodology}

\subsection{Questionnaire}

For this study an online questionnaire has been created, which was distributed through several online channels (like social networks, newsletters) as well as "offline" through word-of-mouth advertising. The questionnaire was only published in German. Technically, the quasi interval/metric characteristics of the (7-point) Likert scale offered for hypothesis testing of mean and median responses and t-test approaches. Numerical values were assigned to the response categories of the questionnaire for modelling equidistant intervals [15].

\subsection{Methods of Evaluation}

The mean values (median, mean including standard deviation (SD)) were calculated by using the Statistical Package of the Social Sciences (SPSS). The significance was calculated with the T-test for independent samples, the confidence level of the difference was set at $95 \%$, so that the significance value (p) was supposed to be less than 0.05 to be considered significant. The Levene Test was per- 
formed to check the data for homogeneity of variances. Free text answer options were analyzed manually to clean up the data.

\section{Discussion}

\subsection{Findings}

The survey was anonymous and conducted from 17th June to 9th August 2015 by using the tool Umfrage Online. From a total of 1107 participants, 1001 completed the study (36.8\% were male, $63.2 \%$ female; aged 14 - 87 years). The age distribution by gender presented a mean age of 29.4 years for women and 31.6 for men. As an additional parameter, the country of origin was asked for within the demographic part of the questionnaire. The respondents $(n=1001)$ came from Germany (93.7\%), other European countries (4.6\%), Asia (1.1\%), Africa $(0.3 \%)$, United States $(0.3 \%)$. The majority $(44.7 \%)$ of all respondents has a high-school diploma. The daily use of the internet takes up four hours $(59.9 \%$ of all respondents). $99.5 \%$ of respondents use the internet for social relations.

\subsection{Hypothesis Results}

The perception of and the interaction with advertisements on Facebook and Google's Search Engine Result Page (SERP) were compared.

H1a: Digital Natives perceive online adverts rather than Digital Immigrants. Not confirmed.

The perception of advertising on Facebook as well as on the Google SERP is not significantly different between Digital Immigrants and Digital Natives (see Table 1), wherefore hypothesis 1a could not be confirmed. Digital Natives and Digital Immigrants perceive the adverts on Facebook (median: 3) and the Google SERP (median: 4) approximately equal.

H1b: Digital Natives interact more often with digital adverts on Facebook than Digital Immigrants-Confirmed for clicks on adverts on Facebook pages and confirmed for likes and shares of sponsored posts.

Digital Immigrants like to click slightly more on Facebook's advertisements than Digital Natives, this result is significant. The results for purchases differ with an assumed equal variance of 0.585 and are not significantly different (t-test, p $(0.778)>0.05$ ) (see Table 2), anyway Digital Natives as well as Digital Immigrants purchase products and/or services through advertisements on $\mathrm{Fa}$ cebook (median: 1$)$.

Table 1. Advertising perception: digital natives vs. digital immigrants.

\begin{tabular}{ccccc}
\hline \multirow{2}{*}{ Platform } & Generational cohorts & \multicolumn{2}{c}{ Statistical distributions } \\
\cline { 2 - 5 } & & Mean (S.D.) & Median & Significance \\
\hline \multirow{2}{*}{ Facebook $(\mathrm{n}=967)$} & Digital Natives $\left(\mathrm{n}_{\mathrm{DN}}=799\right)$ & $3.22(1.494)$ & 3.00 & NS \\
& Digital Immigrants $\left(\mathrm{n}_{\mathrm{DI}}=202\right)$ & $3.23(1.414)$ & 3.00 & \\
Google SERP $(\mathrm{n}=988)$ & Digital Natives $\left(\mathrm{n}_{\mathrm{DN}}=792\right)$ & $3.95(1.930)$ & 4.00 & NS \\
& Digital Immigrants $\left(\mathrm{n}_{\mathrm{DI}}=196\right)$ & $3.78(1.921)$ & 4.00 & \\
\hline
\end{tabular}

a. Scale: never (1), rarely (2), rare (3), occasionally (4), more frequently (5), often (6), always (7). 
The results show that the click activity of Digital Natives and Digital Immigrants on sponsored posts on Facebook is not significant. However, the analysis shows that Digital Immigrants like sponsored posts more than Digital Natives. This result is assumed with an equal variance of 0.155 ( $t$-test, $p(0.046)<0.05$ ). The user group of Digital Immigrants share sponsored posts more often than Digital Natives; this result is highly significant ( $t$-test, $p(0.009)<0.05)$. Regarding sponsored posts on Facebook, the empirical study shows that Digital Immigrants present slightly higher interaction rates than Digital Natives (see Table 3).

$\mathrm{H} 2$ : Women perceive online advertising rather than men. Confirmed for Facebook, not for Google.

The perception of advertising on Facebook is significantly different between male and female respondents (t-test, $\mathrm{p}(0.000)<0.05)$ (see Table 4). Female respondents perceive advertisements on Facebook more often than males. The

Table 2. Comparison of digital natives and digital immigrants regarding the interaction with ads on Facebook (page).

\begin{tabular}{ccccc}
\hline \multirow{2}{*}{ Action } & Generational cohorts & \multicolumn{2}{c}{ Statistical distributions } \\
\cline { 2 - 5 } & & Mean (S.D.) & Median & Significance \\
\hline \multirow{2}{*}{ Click $(\mathrm{n}=785)$} & Digital Natives $\left(\mathrm{n}_{\mathrm{DN}}=635\right)$ & $1.60(0.927)$ & 1.00 & $*$ \\
& Digital Immigrants $\left(\mathrm{n}_{\mathrm{DI}}=150\right)$ & $1.79(0.966)$ & 2.00 & \\
Purchase $(\mathrm{n}=784)$ & Digital Natives $\left(\mathrm{n}_{\mathrm{DN}}=634\right)$ & $1.48(0.830)$ & 1.00 & NS \\
& Digital Immigrants $\left(\mathrm{n}_{\mathrm{DI}}=150\right)$ & $1.46(0.783)$ & 1.00 & \\
\hline
\end{tabular}

a. Scale: never (1), rarely (2), rare (3), occasionally (4), more frequently (5), often (6), always (7).

Table 3. Comparison of digital natives and digital immigrants regarding the interaction with sponsored posts on Facebook.

\begin{tabular}{|c|c|c|c|c|}
\hline \multirow{2}{*}{ Action } & \multirow[t]{2}{*}{ Generational cohorts } & \multicolumn{3}{|c|}{ Statistical distributions } \\
\hline & & Mean (S.D.) & Median & Significance \\
\hline \multirow{2}{*}{ Click $(\mathrm{n}=768)$} & Digital Natives $\left(\mathrm{n}_{\mathrm{DN}}=623\right)$ & $1.95(1.098)$ & 2.00 & \multirow{2}{*}{ NS } \\
\hline & Digital Immigrants $\left(\mathrm{n}_{\mathrm{DI}}=145\right)$ & $2.08(1.137)$ & 2.00 & \\
\hline \multirow{2}{*}{ Like $(\mathrm{n}=768)$} & Digital Natives $\left(\mathrm{n}_{\mathrm{DN}}=623\right)$ & $1.59(0.968)$ & 1.00 & \multirow{2}{*}{ * } \\
\hline & Digital Immigrants $\left(\mathrm{n}_{\mathrm{DI}}=145\right)$ & $1.77(1.059)$ & 1.00 & \\
\hline \multirow{2}{*}{ Share $(n=768)$} & Digital Natives $\left(\mathrm{n}_{\mathrm{DN}}=623\right)$ & $1.36(0.804)$ & 1.00 & \multirow{2}{*}{ ** } \\
\hline & Digital Immigrants $\left(\mathrm{n}_{\mathrm{DI}}=145\right)$ & $1.58(0.903)$ & 1.00 & \\
\hline
\end{tabular}

a. Scale: never (1), rarely (2), rare (3), occasionally (4), more frequently (5), often (6), always (7).

Table 4. Comparison of gender category regarding perception of advertising on....

\begin{tabular}{ccccc}
\hline \multirow{2}{*}{ Platform } & Gender & \multicolumn{2}{c}{ Statistical distributions } \\
\cline { 2 - 5 } & & Mean (S.D.) & Median & Significance \\
\hline \multirow{2}{*}{ Facebook $(\mathrm{n}=967)$} & female $\left(\mathrm{n}_{\mathrm{f}}=624\right)$ & $3.35(1.446)$ & 3.00 & $* * *$ \\
& male $\left(\mathrm{n}_{\mathrm{m}}=363\right)$ & $2.99(1.509)$ & 2.00 & \\
Google SERP $(\mathrm{n}=988)$ & female $\left(\mathrm{n}_{\mathrm{f}}=624\right)$ & $3.94(1.884)$ & 4.00 & NS \\
\hline
\end{tabular}

a. Scale: never (1), rarely (2), rare (3), occasionally (4), more frequently (5), often (6), always (7). 
perception of advertising on the Google SERP is not significantly different between male and female survey participants ( $t$-test, $p(0.552)>0.05)$. Considering the outliers, the statistical distributions give information that women perceive adverts on the Google SERP slightly more than men. Hypothesis 2 was confirmed only for Facebook.

H3a: Women interact more often with digital adverts on Facebook than menConfirmed for purchases of adverts on Facebook pages.

The differences between males and females regarding click interaction are statistically not significant (t-test, $\mathrm{p}(0.340)>0.05)$ (see Table 5). Women rather make a purchase due to Facebook adverts more often than men, this result is significant.

Regarding interactions with sponsored posts on Facebook, there are no significant differences between the genders (see Table 6). The interaction rate with sponsored posts on Facebook of both sexes is equal (median: 2 for click, 1 for like and share).

Women interact a little more frequently with offers on Facebook than men, no significant differences between the genders could be recognized (see Table 7). The interaction rates with offers on Facebook are equal between the genders (median: 2 for click, 1 for like, share and purchase).

H3b: Women interact more often with digital adverts on Google's search engine result page than men-Confirmed for purchases on Google SERP.

Table 5. Comparison of female and male respondents with respect to the interaction with ads on Facebook (page).

\begin{tabular}{|c|c|c|c|c|}
\hline \multirow{2}{*}{ Action } & \multirow[t]{2}{*}{ Gender } & \multicolumn{3}{|c|}{ Statistical distributions } \\
\hline & & Mean (S.D.) & Median & Significance \\
\hline \multirow{2}{*}{ Click $(n=785)$} & female $\left(n_{f}=529\right)$ & $1.65(0.910)$ & 1.00 & \multirow{2}{*}{ NS } \\
\hline & male $\left(\mathrm{n}_{\mathrm{m}}=256\right)$ & $1.59(0.990)$ & 1.00 & \\
\hline \multirow{2}{*}{ Purchase $(n=784)$} & female $\left(n_{f}=529\right)$ & $1.52(0.833)$ & 1.00 & \multirow{2}{*}{ * } \\
\hline & male $\left(\mathrm{n}_{\mathrm{m}}=255\right)$ & $1.39(0.790)$ & 1.00 & \\
\hline
\end{tabular}

a. Scale: never (1), rarely (2), rare (3), occasionally (4), more frequently (5), often (6), always (7).

Table 6. Comparison of female and male respondents with respect to the interaction with sponsored posts on Facebook.

\begin{tabular}{|c|c|c|c|c|}
\hline \multirow{2}{*}{ Action } & \multirow[t]{2}{*}{ Gender } & \multicolumn{3}{|c|}{ Statistical distributions } \\
\hline & & Mean (S.D.) & Median & Significance \\
\hline \multirow{2}{*}{ Click $(\mathrm{n}=768)$} & female $\left(n_{f}=496\right)$ & $1.99(1.082)$ & 2.00 & \multirow{2}{*}{ NS } \\
\hline & male $\left(\mathrm{n}_{\mathrm{m}}=272\right)$ & $1.95(1.150)$ & 2.00 & \\
\hline \multirow{2}{*}{ Like $(n=768)$} & female $\left(n_{f}=496\right)$ & $1.63(0.970)$ & 1.00 & \multirow{2}{*}{ NS } \\
\hline & male $\left(\mathrm{n}_{\mathrm{m}}=272\right)$ & $1.62(1.021)$ & 1.00 & \\
\hline \multirow{2}{*}{ Share $(\mathrm{n}=768)$} & female $\left(n_{f}=496\right)$ & $1.41(0.843)$ & 1.00 & \multirow{2}{*}{ NS } \\
\hline & male $\left(\mathrm{n}_{\mathrm{m}}=272\right)$ & $1.39(0.798)$ & 1.00 & \\
\hline
\end{tabular}

a. Scale: never (1), rarely (2), rare (3), occasionally (4), more frequently (5), often (6), always (7). 
Female respondents click slightly more on adverts on the Google SERP than male (see Table 8) (median: 2, 5 for women and 2 for men), regarding this interaction, no detectable (significant) differences were recorded. Males purchase products and/or services based on advertisements more on the Google SERP than females, this result is significant.

\section{Summary}

The results show that there are some noticeable differences between the acceptance of personalized and context-specific advertising: Prominent are the results of interaction with personalized and context-specific advertising regarding female individuals. Personalized adverts on Facebook are perceived more often from women than from men. Women are the main target group, which make a purchase on basis of advertising of Facebook pages. Male respondents provide a higher purchase rate to adverts on the Google SERP.

While personalized advertising is tailored to the user, these adverts trigger a purchase less often than context-based. This is probably the case due to contextbased advertising being displayed in the active search process of the user, therefore the user is looking for information or offers. The advertisements are sorted by relevance and in the best case the user can thereby be conducted directly to the desired goal. In contrast to the above described context-based advertising,

Table 7. Comparison of female and male respondents with respect to the interaction with offers on Facebook.

\begin{tabular}{|c|c|c|c|c|}
\hline \multirow{2}{*}{ Action } & \multirow[t]{2}{*}{ Gender } & \multicolumn{3}{|c|}{ Statistical distributions } \\
\hline & & Mean (S.D.) & Median & Significance \\
\hline \multirow{2}{*}{ Click $(n=768)$} & female $\left(n_{f}=284\right)$ & $2.08(1.231)$ & 2.00 & \multirow{2}{*}{ NS } \\
\hline & male $\left(\mathrm{n}_{\mathrm{m}}=138\right)$ & $2.01(1.190)$ & 2.00 & \\
\hline \multirow{2}{*}{ Like $(\mathrm{n}=768)$} & female $\left(n_{f}=284\right)$ & $1.78(1.139)$ & 1.00 & \multirow{2}{*}{ NS } \\
\hline & male $\left(\mathrm{n}_{\mathrm{m}}=138\right)$ & $1.68(1.114)$ & 1.00 & \\
\hline \multirow{2}{*}{ Share $(n=768)$} & female $\left(n_{f}=284\right)$ & $1.54(0.945)$ & 1.00 & \multirow{2}{*}{ NS } \\
\hline & male $\left(\mathrm{n}_{\mathrm{m}}=138\right)$ & $1.49(0.976)$ & 1.00 & \\
\hline \multirow{2}{*}{ Purchase $(n=422)$} & female $\left(n_{f}=284\right)$ & $1.69(1.057)$ & 1.00 & \multirow{2}{*}{ NS } \\
\hline & male $\left(\mathrm{n}_{\mathrm{m}}=138\right)$ & $1.66(1.036)$ & 1.00 & \\
\hline
\end{tabular}

a. Scale: never (1), rarely (2), rare (3), occasionally (4), more frequently (5), often (6), always (7).

Table 8. Comparison of female and male respondents with respect to the interaction on the Google SERP.

\begin{tabular}{ccccc}
\hline \multirow{2}{*}{ Action } & Gender & \multicolumn{2}{c}{ Statistical distributions } \\
\cline { 2 - 4 } & & Mean (S.D.) & Median & Significance \\
\hline \multirow{2}{*}{ Click $(\mathrm{n}=847)$} & female $\left(\mathrm{n}_{\mathrm{f}}=544\right)$ & $2.67(1.297)$ & 2.50 & \multirow{2}{*}{ NS } \\
& male $\left(\mathrm{n}_{\mathrm{m}}=303\right)$ & $2.75(1.445)$ & 2.00 & \\
Purchase $(\mathrm{n}=847)$ & female $\left(\mathrm{n}_{\mathrm{f}}=544\right)$ & $2.00(1.201)$ & 2.00 & $*$ \\
\hline
\end{tabular}

a. Scale: never (1), rarely (2), rare (3), occasionally (4), more frequently (5), often (6), always (7). 
display adverts in social networks are often faced mistrust, because of uncertainties regarding the use of personal data.

In general, this study discovered that both personalized and context-based advertising are generally not being rejected. It seems indifferent to the users to whether they will be shown adverts or not. Digital commercials are sometimes perceived and most of the time users interact extensively with them so that they will not be perceived disturbing or negative. Another indication of the acceptance of the user is the increased interaction with context-specific adverts. While the focus of the present work is focused on user' acceptance, a constituent or complementary research could discover in what way the actual impact of advertising can be assessed. To investigate this impact, more data for example from internal statistics of advertiser or advertising data platforms such as Facebook and Google are needed.

\section{References}

[1] Evans, D.S. (2008) The Economics of the Online Advertising Industry. Review of Network Economics, 7, 359-391. https://doi.org/10.2202/1446-9022.1154

[2] Yaakop, A., Anuar, M.M. and Omar, K. (2013) Like It or Not: Issue of Credibility in Facebook Advertising. Asian Social Science, 9, 154-163.

https://doi.org/10.5539/ass.v9n3p154

[3] Yaakop, A. and Hemsley-Brown, J. (2011) Attitudes towards Advertising: Does Traditional Media still have its Place in the Future? Proceedings of 1 st International Conference on Accounting, Business and Economics, Terengganu, 1-2 December 2011, 5.

[4] Zogby Analytics (2016) Public Opinion Survey on Value of the Ad-Supported Internet. Poll.

[5] Linde, F. and Stock, W.G. (2011) Information Markets-A Strategic Guideline for the I-Commerce. De Gruyter Saur, Berlin. https://doi.org/10.1515/9783110236101

[6] Boyd, D.M. and Ellison, N.B. (2007) Social Network Sites: Definition, History, and Scholarship. Journal of Computer-Mediated Communication, 13, 210-230. https://doi.org/10.1111/j.1083-6101.2007.00393.x

[7] Campbell, D.E. and Wright, R.T. (2008) Shut-Up I Don't Care: Understanding the Role of Relevance and Interactivity on Consumer Attitudes toward Repetitive Online Advertising. Journal of Electronic Commerce Research, 9, 62-76.

[8] Hadija, Z. (2008) Perceptions of Advertising in Online Social Networks: In-Depth Interviews. PhD Thesis, College of Liberal Arts, Rochester.

[9] Fietkiewicz, K.J., Lins, E., Baran, K.S. and Stock, W.G. (2016) Inter-Generational Comparison of Social Media Use: Investigating the Online Behavior of Different Generational Cohorts. Proceedings of 49 th Hawaii International Conference on System Sciences, Koloa, 5-8 January 2016, 3829-3838. https://doi.org/10.1109/hicss.2016.477

[10] Prensky, M. (2001) Digital Natives, Digital Immigrants Part 1. On the Horizon, 9, 1-6. https://doi.org/10.1108/10748120110424816

[11] Geddes, B. (2014) Advanced Google AdWords. 3rd Edition, John Wiley \& Sons, Indianapolis.

[12] Van Slyke, C., Comunale, C.L. and Belanger, F. (2002) Gender Differences in Perceptions of Web-Based Shopping. Communications of the ACM-Envolving data 
Mining into Solutions for Insights, 45, 82-86.

[13] Garbarino, E. and Strahilevitz, M. (2004) Gender Differences in the Perceived Risk of Buying Online and the Effects of Receiving a Site Recommendation. Journal of Business Research, 57, 768-775. https://doi.org/10.1016/S0148-2963(02)00363-6

[14] Bannister, A., Kiefer, J. and Nellums, J. (2013) College Student's Perceptions of and Behaviors Regarding Facebook Advertising: An Exploratory Study. The Catalyst, 3, $1-20$.

[15] Ary, D., Jacobs, L.C. and Razavieh, A. (1996) Introduction to Research in Education. Harcourt Brace College Publishers, Fort Worth.

Submit or recommend next manuscript to SCIRP and we will provide best service for you:

Accepting pre-submission inquiries through Email, Facebook, LinkedIn, Twitter, etc. A wide selection of journals (inclusive of 9 subjects, more than 200 journals) Providing 24-hour high-quality service User-friendly online submission system Fair and swift peer-review system Efficient typesetting and proofreading procedure Display of the result of downloads and visits, as well as the number of cited articles Maximum dissemination of your research work

Submit your manuscript at: http://papersubmission.scirp.org/ Or contact jss@scirp.org 